\title{
Persistent Ependymal Tumor Arising from an Immature Ovarian Teratoma: A Rare Case
}

\author{
Anoshia Afzal *D, Rufei Lu, Sepideh N. Asadbeigi, Kar-Ming Fung and Jo Elle G. Peterson \\ Department of Pathology, University of Oklahoma Health Sciences Center, Oklahoma City, OK 73104, USA; \\ Rufei-Lu@ouhsc.edu (R.L.); Asadbeigi.md@gmail.com (S.N.A.); KarMing-Fung@ouhsc.edu (K.-M.F.); \\ JoElle-Peterson@ouhsc.edu (J.E.G.P.) \\ * Correspondence: anoshia.afzal@hotmail.com
}

Received: 4 October 2020; Accepted: 30 October 2020; Published: 3 November 2020

\begin{abstract}
Primary ovarian ependymoma is a rare neuroectodermal neoplasm that can arise from immature ovarian teratoma. Due to the paucity of this entity, a complete molecular analysis of these tumors has not been done, thus creating a challenge for finding an effective and safe therapeutic treatment. In the limited literature, patients with primary ovarian ependymoma showed various responses to an array of individualized therapies, ranging from surgeries to chemotherapies. Here, we present a 38-year-old female with persistent ovarian ependymoma, with a molecular profile similar to traditional central nervous system ependymoma that is irresponsive to multiple cytoreduction and clinical experimental therapies. Therefore, a prompt recognition and reporting of this entity can greatly aid in expanding the understanding and standardization of therapies for this neoplasm.
\end{abstract}

Keywords: ependymoma; teratoma; ovarian; immature teratoma

\section{Introduction}

Ependymoma is a glial neoplasm with ependymal differentiation that primarily arises in the central nervous system. However, central nervous system (CNS)-type tumors can rarely arise from ovarian immature teratoma. The first ovarian ependymoma was reported by Kleinman and colleagues in 1984 [1]. Since then, few cases of primary ovarian ependymoma have been reported in the literature [2,3]. Primary ovarian ependymoma is thus classified as a neuroectodermal tumor arising from pluripotent stem cells of Mullerian origin, according to female reproductive tumor classification. Limited studies suggest that there may be a difference in the molecular profiles of CNS and extra-axial ependymoma [4].

\section{Case Presentation}

Our patient is a 38-year-old female with a past medical history significant for profound vision loss since age 12 due to retinitis pigmentosa, who initially presented with multiple pelvic masses with suspicion of omental metastatic disease in May of 2016. The initial tumor marker panel revealed an elevated CA (cancer antigen) of $379 \mathrm{U} / \mathrm{mL}$, normal CA19-9 (12 U/mL), CEA (carcinoembryonic antigen) of $<0.5 \mathrm{ng} / \mathrm{mL}$, and hCG (human chorionic gonadotropin) of $<1 \mathrm{ng} / \mathrm{mL}$. A cytology specimen of interventional radiology-guided paracentesis showed cellular samples with atypical cells positive for CK(cytokeratin)7 and negative for homeobox protein CDX-2, CK(cytokeratin)20, chromogranin, and TTF(thyroid transcription factor) -1 .

The patient underwent laparoscopic diagnostic biopsy and paracentesis with intra-operative impression of suspected stage III ovarian tumor and unresectable disease. Microscopic sections of the abdominal wall and falciform ligament tumor revealed round to oval nuclei with a fine "salt and pepper" chromatin pattern, perivascular pseudo rosette formation, and rare true ependymal 
rosette formation (Figure 1A-D). There were areas of elevated mitotic activity, vascular proliferation and necrosis. Multiple architectural patterns, including classical, papillary and clear cell areas, were present. Tumor cells were diffusely positive for Glial fibrillary acidic protein (GFAP) (Figure 1E) with characteristic dot-like Epithelial Membrane Antigen (EMA) positivity (Figure 1F) and focal positivity for CK7 (Figure 1G). Genomic evaluation using achromosomal microarray revealed an abnormal gain of 15q11.1q13.1, a gain of15q22.2q26.3, a gain of chromosomes 4, 7, 8, 9, 10, 12, 14, 16, 18, 20, 21, and X, and a loss of chromosomes 6, 17 and 22.The Neuro-Onc Expanded Panel was negative for any significant gene mutations including RELA, YAP1, C11orf95, TERT, H3F3A, and NF2.The final pathology report was consistent with a WHO Grade 3 ependymal tumor of unclear origin, perhaps arising from an immature teratoma. The gynecology oncology consultantdecided not to perform further surgery or debulking as the disease was unresectable, and decided to go for chemotherapy.
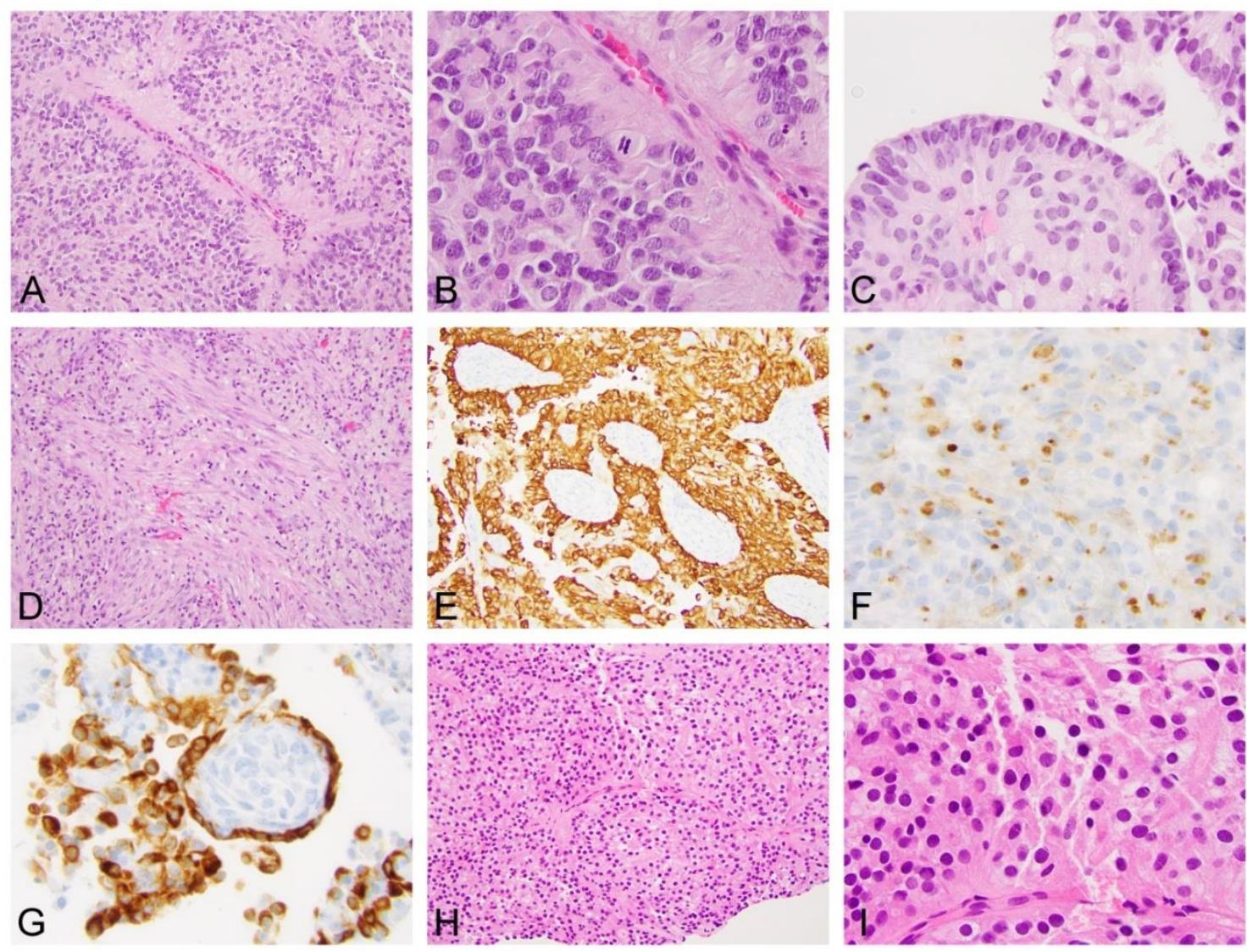

Figure 1. Sections from initial biopsy (A-D) highlight a solid tumor with cells having round to oval nuclei and stippled chromatin, perivascular pseudo-rosette, and rare true ependymal rosette formation. Tumor cells show diffuse positivity for GFAP (E), characteristic dot-like positivity for EMA (F) and focal positivity for CK7 (G). A repeat peritoneal biopsy (H,I) on 1 July 2020 showed persistent disease.

The patient was placed on Bleomycin, Cisplatin and Etoposide combination chemotherapy from June of 2016 to September of 2016. Bleomycin was later discontinued due to significant pulmonary side effects. A repeat biopsy on 27 September 2016 confirmed persistent disease. The patient was started on Cetuximab and CHK1/2 inhibitor, but she had reactions to both drugs, so they were discontinued. The patient was later started on trial RM 314 (oral topotecan + LCL161 $\times 38$ cycles) and showed only a mild improvement with persistent disease on her CT scan of the abdomen on 28 May 2019 (i.e., a $1.4 \mathrm{~cm}$ umbilical nodule), so the same chemotherapy regimen was continued for 53 cycles. A repeat peritoneal biopsy (Figure 1H,I) on 1 July 2020 showed similar histological features as her previous biopsy, and was consistent with persistent disease. The patient was subsequently placed on 
phase 1 RM 599 trial (Avelumab and oral DNA-PK inhibitor) in July of 2020 and her repeat CT of the abdomen on 3 September 2020 was consistent with stable disease.

\section{Discussion}

Ependymoma is a glial neoplasm with ependymal differentiation that primarily arises in the central nervous system. However, central nervous system (CNS)-type tumors can rarely arise from ovarian immature teratoma and can be molecularly and cytogenetically identical or different from CNS ependymomas.

The most commonly reported cytogenetic alterations in adult CNS ependymoma include the loss of chromosomes 6, 10,13q,14q, 16 and 22/22q and the gain of chromosomes 2, 5, 7, 9, 12, 18, and $X$, with gains of 7 and 9 and the loss of 22q being the most common alterations reported [4-7]. Among molecular/genomic mutations/alterations, the most commonly identified upregulated oncogenes are WNT5A, TP53 homologue TP63, the transcription factor ZIC1, the angiogenesis factor VEGF, COL4A1, IBP2, HOX7, WEE1, and GAC1. The most frequent tumor suppressor genes which are found to be down-regulated include the A/F2-interacting gene SCHIP-1, the APC-associated gene EB1, and genes that are involved in vesicle trafficking and recycling, such as NPC1, RAB40B, TJ2 and SH3GL3 [8,9]. Modena et al. and Palm et al. also illustrated the high-level expression of genes involved in Notch signaling, as well as the over-expression of numerous HOX genes in both spinal and intracranial ependymomas. Additionally, intracranial ependymomas were reported to have up-regulated sonic hedgehog $(\mathrm{SHH})$ and bone morphogenetic protein (BMP) pathway members $[10,11]$.

The comprehensive molecular analysis of our case revealed genetic abnormalities that are compatible with CNS ependymoma, suggesting a larger cohort consisting of the two entities with comprehensive molecular analysis is warranted to fully characterize the two seemingly distinct entities. However, it is unclear whether our patient has an ependymoma arising from ovarian teratoma due to the unresectable nature of disease upon presentation. Due to the rarity of this entity and the lack of complete molecular analysis of these neoplasms, there is no standardized therapeutic treatment available for ovarian ependymoma. The treatment of extra-axial ependymomas is currently individualized, which can include surgical debulking with adjuvant chemotherapy, a surgical approach combined with adjuvant chemotherapy and radiation [4], or treatment with approved or clinical experimental chemotherapies [4]. These different therapeutic approaches have shown various degrees of success likely due to different onset disease stages and extents of the tumor involvement [12,13]. Some cases of ovarian ependymoma can be satisfactorily treated with surgery without chemotherapy. It is therefore important to be able to differentiate primary ovarian ependymoma from CNS ependymoma. Our patient had a molecular profile similar to CNS ependymoma and this might have contributed to the reason why she did not respond initially. A larger cohort with comprehensive molecular analysis is warranted to clarify the abnormal molecular events leading to these neoplasms.

\section{Conclusions}

Encountering a low metastatic potential CNS tumor extra-axially should prompt the investigation of a possible associated germ cell tumor. An accurate and rapid recognition and reporting of neuroectodermal tumors arising from the gynecologic tract with comprehensive molecular analysis of the primary tumor and recurrence is vitally important for expanding the knowledge of these extra-axial CNS tumors, and searching for an effective standardized therapy.

Author Contributions: All authors contributed to writing up the manuscript and gathering information but the first and second authors did most of the work. All authors have read and agreed to the published version of the manuscript.

Funding: This research received no external funding.

Conflicts of Interest: The authors declare no conflict of interest. 
Ethical Statement: No patient identifying information is present in the case report. The patient was informed and verbal consent was obtained about publishing the case report anonymously.

\section{References}

1. Kleinman, G.M.; Young, R.H.; Scully, R.E. Ependymoma of the ovary: Report of three cases. Hum. Pathol. 1984, 15, 632-638. [CrossRef]

2. Takano, T.; Akahira, J.; Moriya, T.; Murakami, T.; Tanaka, M.; Goto, M.; Niikura, H.; Ito, K.; Mikami, Y.; Okamura, K.; et al. Primary ependymoma of the ovary: A case report and literature review. Int. J. Gynecol. Cancer 2005, 15, 1138-1141. [CrossRef] [PubMed]

3. Stolnicu, S.; Furtado, A.; Sanches, A.; Nicolae, A.; Preda, O.; Hincu, M.; Nogales, F.F. Ovarian ependymomas of extra-axial type or central immunophenotypes. Hum. Pathol. 2011, 42, 403-408. [CrossRef] [PubMed]

4. Liang, L.; Olar, A.; Niu, N.; Jiang, Y.; Cheng, W.; Bian, X.-W.; Yang, W.; Zhang, J.; Yemelyanova, A.; Malpica, A.; et al. Primary Glial and Neuronal Tumors of the Ovary or Peritoneum. Am. J. Surg. Pathol. 2016, 40, 847-856. [CrossRef] [PubMed]

5. Mack, S.C.; Taylor, M.D. The genetic and epigenetic basis of ependymoma. Childs Nerv. Syst. 2009, 25, 1195-1201. [CrossRef] [PubMed]

6. Carter, M.; Nicholson, J.; Ross, F.; Crolla, J.; Allibone, R.; Balaji, V.; Perry, R.; Walker, D.; Gilbertson, R.; Ellison, D.W. Genetic abnormalities detected in ependymomas by comparative genomic hybridisation. Br. J. Cancer 2002, 86, 929-939. [CrossRef] [PubMed]

7. Mazewski, C.; Soukup, S.; Ballard, E.; Gotwals, B.; Lampkin, B. Karyotype studies in 18 ependymomas with literature review of 107 cases. Cancer Genet. Cytogenet. 1999, 113, 1-8. [CrossRef]

8. Yao, Y.; Mack, S.C.; Taylor, M.D. Molecular genetics of ependymoma. Chin. J. Cancer 2011, 30, 669-681. [CrossRef] [PubMed]

9. Pajtler, K.W.; Witt, H.; Sill, M.; Jones, D.T.; Hovestadt, V.; Kratochwil, F.; Wani, K.; Tatevossian, R.; Punchihewa, C.; Johann, P.; et al. Molecular Classification of Ependymal Tumors across All CNS Compartments, Histopathological Grades, and Age Groups. Cancer Cell 2015, 27, 728-743. [CrossRef] [PubMed]

10. Modena, P.; Lualdi, E.; Facchinetti, F.; Veltman, J.; Reid, J.F.; Minardi, S.; Janssen, I.; Giangaspero, F.; Forni, M.; Finocchiaro, G.; et al. Identification of tumor-specific molecular signatures in intracranial ependymoma and association with clinical characteristics. J. Clin. Oncol. 2006, 24, 5223-5233. [CrossRef]

11. Palm, T.; Figarella-Branger, D.; Chapon, F.; Lacroix, C.; Gray, F.; Scaravilli, F.; Ellison, D.W.; Salmon, I.; Vikkula, M.; Godfraind, C.; et al. Expression profiling of ependymomas unravels localization and tumor grade-specific tumorigenesis. Cancer 2009, 115, 3955-3968. [CrossRef] [PubMed]

12. Garcia-Barriola, V.; De Gomez, M.N.; Suarez,J.A.; Lara, C.; González, J.E.; García-Tamayo, J. Ovarian Ependymoma. A Case Report. Pathol. Res. Pract. 2000, 196, 595-599. [CrossRef]

13. Yuan, Z.; Yu, M.; Chen, Y. Individualized treatment for a case of recurrent ovarian ependymoma. OncoTargets Ther. 2018, 12, 113-117. [CrossRef] [PubMed]

Publisher's Note: MDPI stays neutral with regard to jurisdictional claims in published maps and institutional affiliations.

(C) 2020 by the authors. Licensee MDPI, Basel, Switzerland. This article is an open access article distributed under the terms and conditions of the Creative Commons Attribution (CC BY) license (http://creativecommons.org/licenses/by/4.0/). 